\title{
KEANEKARAGAMAN AMPHIBIA DI KAMPUS UNIVERSITAS SAM RATULANGI
}

\author{
Greace Kurniawati Lindo $^{1)^{*}}$, Deidy Yulius Katili ${ }^{1)}$, Lalu Wahyudi ${ }^{1)}$ \\ ${ }^{1)}$ Program Studi Biologi, FMIPA Universitas Sam Ratulangi Manado
}

\begin{abstract}
ABSTRAK
Amphibia merupakan hewan bertulang belakang yang hidup di dua alam yaitu air dan darat. Amphibia terdiri dari tiga ordo, yaitu Caecilia, Caudata dan Anura. Sebagian besar amphibia mempunyai anggota gerak seperti tungkai dan jari-jari. Penelitian ini bertujuan untuk menentukan tingkat keanekaragaman amphibia yang ada di Kampus Universitas Sam Ratulagi Manado berdasarkan nilai indeks Shannon-Wiener. Penelitian ini menggunakan metode purposive sampling yang dilaksanakan pada bulan September-November 2017. Berdasarkan hasil penelitian terdapat enam jenis amphibia yang ditemukan yaitu, Peltophryne lemur, Phrynoidis asper, Ingerophrynus biporcatus, Bufo melanostictus, Bufo bankorensis, dan Bufo gargarizans. Amphibia yang paling banyak ditemukan adalah Phrynoidis asper dan yang paling sedikit ditemukan adalah Bufo bankorensis. Indeks keanekaragaman dari amphibia yang diamati terdapat di kampus Unsrat termasuk dalam kategori sedang dengan nilai indeks 1,783.
\end{abstract}

Kata kunci: Keanekaragaman, Amphibia.

\begin{abstract}
ABSTRAK
Amphibia is a vertebrate animal that lives in two realms: water and land. Amphibia consists of three orders, namely Caecilia, Caudata and Anura. Most amphibians have limbs such as limbs and fingers. This research aims to determine the extent of amphibian diversity that exists at the University Sam Ratulagi Manado campus based on the value of Shannon-Wiener index. The study used purposive sampling methods conducted in September-November 2017. Based on the research results there are six types of amphibia found namely, Peltophryne Lemur, Phrynoidis asper, Ingerophrynus biporcatus, Bufo melanostictus, Bufo bankorensis, and Bufo Gargarizans. The most widely discovered amphibian is Phrynoidis asper and the fewest found is Bufo bankorensis. The diversity index of amphibians observed on the campus of Unsrat is included in the medium with the value of Indeks1,783.
\end{abstract}

Keywords: Diversity, Amphibia. 


\section{PENDAHULUAN}

Indonesia merupakan salah satu pusat keanekaragaman hayati terkaya di dunia. Keanekaragaman hayati adalah suatu ukuran untuk mengetahui kehidupan yang berhubungan erat dengan jumlah spesies suatu komunitas. Keanekaragaman spesies dapat digunakan untuk mengukur stabilitas komunitas, yaitu suatu kemampuan komunitas untuk menjaga dirinya tetap stabil meskipun terdapat gangguan terhadap komponen-komponennya di mana suatu komunitas akan memiliki keanekaragaman spesies yang tinggi jika tersusun oleh banyak spesies (Soegianto, 1994 Indriyanto, 2006).

Sulawesi sebagai salah satu pulau besar, tetapi belum banyak dilakukan penelitian mengenai keberadaan amphibia katak dan kodok. Hal ini antara lain karena kurang dikenalnya hewan ini dimasyarakat umum maupun di kalangan peneliti. Adanya persepsi negatif bahwa kodok adalah hewan beracun dan menjijikkan (Kusrini, 2003) membuat amphibia dijauhi oleh masyarakat. Berdasarkan data dari Global Wildlife Conservation dan International Union for Conservation of Nature (IUCN) sekitar 30-40 persen dari jenis amphibia terancam punah.

Amphibia terdiri dari tiga ordo, yaitu Caecilia, Caudata dan Anura. Sebagian besar amphibia mempunyai anggota gerak seperti tungkai dan jari-jari. Telurnya tidak bercangkag, dan diletakkan dalam air atau tempat yang lembab untuk menghindari kekeringan (Mistar, 2008). Habitat utama adalah hutan primer, hutan sekunder, hutan rawa, sungai besar, sungai sedang, anak sungai, kolam dan danau (Mistar, 2003). Umumnya amphibia dijumpai pada malam hari atau pada musim penghujan. Iskandar (1998) menyatakan bahwa amphibia selalu hidup berasosiasi dengan air sesuai namanya yaitu hidup pada dua alam (di air dan di darat).

Informasi tentang keberadaan amphibia dan penyebaran di daerah Sulawesi Utara masih kurang diketahui dengan pasti. Penelitian tentang amphibia di Sulawesi Utara pernah dilakukan oleh Wiliam Renyaan pada tahun 2006 di daerah cagar alam Tangkoko. Kampus Universitas Sam Ratulangi sedang menggadakan pembanguan di segala bidang melalui pembangunan gedung-gedung fakultas, pelebaran jalan, dan penghijauan yang secara tidak langsung akan mempengaruhi keberadaan amphibia di lokasi kampus. Hal ini dipandang perlu diadakan penelitian tentang keberadaan amphibia menyangkut tingkat keanekaragaman di kawasan kampus Unsrat terdapat beberapa tipe habitat seperti rawa dan kolam, tanah berhutan dan pohon-pohon yang rindah.

\section{METODOLOGI PENILITIAN}

Pengambilan data dilakukan dengan menggunakan metode survei (Bibby et al., 2000) dan teknik pengambilan data menggunakan metode purposive sampling, yaitu teknik penentuan sampel dengan pertimbangan tertentu (Michael, 1995). Metode ini menjelajahi dan menghitung setiap amphibia yang dijumpai di daerah kampus Universitas Sam Ratulangi. Cara mengamati dan mengidentifikasi jenis amphibia yaitu dengan melihat dan mencatat tanda-tanda khusus pada amphibia yang diamati. Seperti suara, bentuk tubuh, morfologi, dan warna tubuh. Tingkah laku dapat juga dijadikan dasar untuk mengenali suatu jenis amphibia.

\section{HASIL DAN PEMBAHASAN Kondisi Lingkungan Lokasi Penelitian}

Berdasarkan lokasi penelitian di Kampus Universitas Sam Ratulangi mempunyai beberapa tipe habitat yang menunjukan amphibia dapat hidup dan berkembang pada berbagai tipe habitat tersebut. Tipe habitat ini berfungsi sebagai tempat berlindung dan mencari makan bagi jenis-jenis amphibia yang ada. Berikut merupakan deskripsi dan tipe-tipe habitat yang menjadi lokasi penelitian di kampus Universitas Sam Ratulangi Habitat tanah berhutan terdapat di Fakultas Matematika dan Ilmu Pengetahuan Alam (MIPA) dimana ditemukan vegetasi pepohonan, perdu, dan semak. Kondisi lingkungan di atas memungkinkan beberapa jenis amphibia dapat hidup pada habitat tersebut. Pada Habitat ini juga dijumpai jenis tumbuhan seperti Swietania mahagoni, Terminalia catappa, dan Areca catechu.

Area Sampling dengan tipe habitat rawa dan kolam yang berada di samping Bank BNI memungkinkan beberapa jenis amphibia dapat hidup dalam kondisi lingkungan yang kolamnya bersifat stabil, basah, lembab dan sejuk. Pada 
habitat ini juga dijumpai beberapa tumbuhan yang terdiri dari Bougainvillea, lilium sp, dan Nymphaea sp.

Area Sampling tanah berhutan tepanya

di Fakultas Kedokteran dengan kondisi lingkungan yang di jumpai pepohonan, semak, serta jenis tumbuhan Delonix regia, Syzygium aqueum, Colocasia esculenta, dan Ananas comosus, ini memungkinkan beberapa amphibia dapat hidup pada habitat tersebut. Lokasi penelitian dengan karakteristik tipe habitat di atas memungkinkan ditemukan amphibia. Berdasarkan hasil penelitian di tiga lokasi tersebut didapatkan Bufo jenis Peltophryne lemur, Phrynoidis asper, Ingerophrynus biporcatus, Bufo melanostictus, Bufo bankorensis, dan Bufo gargarizans.

\section{Indeks Keanekaragaman Amphibia di Kampus Universitas Sam Ratulangi}

Berdasarkan hasil pengamatan jumlah jenis, jumlah individu, serta perhitungan menggunakan indeks Shannon-Wiener di peroleh indeks keanekaragaman amphibia di kampus Universitas Sam Ratulangi dengan nilai 1,783 Nilai ini termasuk kategori sedang. Jenis amphibia yang paling banyak ditemukan yaitu Phrynoidis asper dan paling sedikit ditemukan yaitu Bufo bankorensis. Peningkatan jumlah amphibia yang ditemukan, cenderung meningkat pada bulan November. Hal ini disebabkan karna faktor curah hujan dan ketersediaan air yang cukup disukai oleh kebanyakan amphibia.

Area Sampling dengan tipe habitat tanah berhutan di Fakultas Matematika dan Ilmu Pengetahuan Alam (MIPA) di jumpai 6 spesies amphibia yaitu Phrynoidis asper, Peltophryne lemur, Ingerophrynus biporcatus, Bufo melanostictus, Bufo bankorensis dan Bufo gargarizans. Pada lokasi ini memiliki indeks keanekaragaman sebesar 1,768. Banyaknya jenis amphibia yang ditemukan pada lokasi ini dipengaruhi oleh habitat yang masih terjaga dan jenis-jenis makanan yang masih banyak ditemukan seperti invertebrata kecil, serangga, dan serasah. Hal ini didukung juga oleh (Duellman, Trueb 1994). yang menyatakan bahwa beberapa jenis amphibia menyukai hewan invertebrate kecil dan serasah.

Pada Tipe habitat rawa dan kolam yang terletak di samping Bank BNI di jumpai 6 spesies amphibia yaitu peltophryne lemur, phrynoidis asper, Ingerophrynus biporcatus, Bufo melanostictus, Bufo bankorensis, dan Bufo gargarizans dengan indeks keanekaragaman 1,764. Indeks keanekaragaman pada lokasi ini lebih kurang dari lokasi pertama. Hal ini dikarenakan kondisi lingkungan yang lebih terbuka, dan kondisi air rawa yang tidak mengalir menyebabkan kurang disukainya oleh amphibia dan hewan-hewan lainya seperti serangga yang merupakan sumber makanan dari amphibia. (Fitri et al., 2008; Mumpuni 2011; Phade Ghate 2002). menyatakan bahwa makanan alami amphibia yang utama adalah serangga.

Pada lokasi di Fakultas Kedokteran dengan tipe habitat tanah berhutan hanya di jumpai 5 spesies amphibia yaitu Bufo gargarizans, Peltophryne lemur, Phrynoidis asper, Ingerophrynus biporcatus, dan Bufo bankorensis. Berdasarkan hasil pengamatan pada lokasi ini didapatkan indeks keanekaragaman dengan nilai 1,576, nilai indeks ini kurang dibandingkan dengan dua lokasi lainnya. Hal lain yang mempengaruhi rendahnya keanekaragaman di lokasi ini adalah adanya aktivitas manusia dalam hal pembangunan gedung-gedung, pembuatan got, pengalian dan pengusuran tanah. Kegiatan ini tentu dapat merusak habitat amphibia. Hal ini didukung juga oleh pernyataan dari (Zug 1998) Universitas Sam Ratulangi adalah Phrynoidis asper. Amphibia ini dapat ditemukan di setiap tiap-tipe habitat yang ada dikampus. Phrynoidis asper dapat bertahan hidup karna habitat dan makanan yang masih terjaga. Hal ini diduga selain faktor makanan dan habitat yang sesuai juga prilaku jenis amphibia ini adalah suka melompat dan berpindah tempat sehingga jenis ini terdapat di setiap tipe habitat. Amphibia yang paling sedikit di temukan selama penelitian adalah Bufo bankorensis hal ini dikarenakan amphibia jenis ini lebih menyukai tipe habitat yang banyak pepohonan.

Aktivitas lainya dari amphibia yang dijumpai pada saat penelitian di Kampus Universitas Sam Ratulangi adalah aktivitas diam, bersuara dan melompat. Perilaku berdiam diri adalah salah satu strategi atau cara amphibia mencari mangsa untuk digunakan sebagai makanan. (Duellman, Carpenter 1998). 
PHARMACON- PROGRAM STUDI FARMASI, FMIPA, UNIVERSITAS SAM RATULANGI,

Volume 8 Nomor 3 Agustus 2019

Menyatakan bahwa perilaku diam dan lidahnya yang mengandung lendir. Amphibia menunggu adalah cara amphibia untuk menangkap mangsa dengan menggunakan juga sangat menyukai makanan yang masih hidup dan bergerak

Tabel 1. Lokasi Habitat Tanah berhutan FMIPA

\section{Densitas}

Jenis Amphibia

Jumlah (Ekor/ha) Ni/N $\quad$ Pi $\quad$ Ln pi $\quad$ Pi ln pi $\quad H$

\begin{tabular}{llllllll}
\hline Phrynoidis asper & 452 & 5857.92 & 0.236 & 0.236 & -1.442 & -0.341 & \\
Peltophryne lemur & 330 & 4276.8 & 0.173 & 0.173 & -1.757 & -0.303 & \\
Ingerophrynus biporcatus & 309 & 4004.64 & 0.162 & 0.162 & -1.823 & -0.295 & \\
Bufo melanostictus & 276 & 3576.96 & 0.144 & 0.144 & -1.936 & -0.279 & 1.768 \\
Bufo bankorensis & 219 & 2838.24 & 0.115 & 0.115 & -2.167 & -0.248 & \\
Bufo gargarizans & 326 & 4224.96 & 0.171 & 0.171 & -1.769 & -0.302 \\
Total & 1912 & 24779.52 & 1 & 1 & -10.893 & -1.768 \\
\hline
\end{tabular}

Tabel 2. Lokasi habitat Rawa Samping BNI

\begin{tabular}{llllllll}
\hline & Densitas & & & & & & \\
Jenis Amphibia & Jumlah & (Ekor/ha) & Ni/N & Pi & Ln pi & Pi ln pi & H \\
\hline Peltophryne lemur & 327 & 2014.974 & 0.199 & 0.199 & -1.613 & -0.321 & \\
Phrynoidis asper & 192 & 1183.104 & 0.117 & 0.117 & -2.146 & -0.251 & \\
Ingerophrynus biporcatus & 252 & 1552.824 & 0.154 & 0.154 & -1.874 & -0.288 & \\
Bufo melanostictus & 385 & 2372.37 & 0.235 & 0.235 & -1.450 & -0.340 & 1.764 \\
Bufo bankorensis & 263 & 1620.606 & 0.160 & 0.160 & -1.831 & -0.293 & \\
Bufo gargarizans & 222 & 1367.964 & 0.135 & 0.135 & -2.000 & -0.271 & \\
Total & 1641 & 10111.84 & 1 & 1 & -10.913 & -1.764 & \\
\hline
\end{tabular}


Tabel 3. Lokasi Tanah Berhutan Fakultas Kedokteran

\begin{tabular}{llllllll}
\hline & Densitas & & & & & & \\
Jenis Amphibia & Jumlah & (Ekor/ha) & $\mathrm{Ni} / \mathrm{N}$ & $\mathrm{Pi}$ & Ln pi & Pi ln pi & $\mathrm{H}$ \\
\hline Bufo gargarizans & 345 & 965.035 & 0.291 & 0.291 & -1.235 & -0.359 & \\
Peltophryne lemur & 190 & 531.4685 & 0.160 & 0.160 & -1.831 & -0.293 & \\
Phrynoidis asper & 266 & 744.0559 & 0.224 & 0.224 & -1.495 & -0.335 & \\
Ingerophrynus biporcatus & 212 & 593.007 & 0.179 & 0.179 & -1.722 & -0.308 & \\
Bufo bankorensis & 173 & 483.9161 & 0.146 & 0.146 & -1.925 & -0.281 & \\
Total & 1186 & 3317.483 & 1 & 1 & -8.208 & -1.576 & \\
\hline
\end{tabular}

Tabel 4. Indeks Keanekaragaman Amphibia di Kampus Universitas Sam Ratulangi

\begin{tabular}{llllllll}
\hline \multirow{2}{*}{ Jenis Amphibia } & Densitas & & & & & & \\
& Jumlah & (Ekor/ha) & $\mathrm{Ni} / \mathrm{N}$ & $\mathrm{Pi}$ & Ln pi & Pi ln pi & $\mathrm{H}$ \\
\hline Peltophryne lemur & 657 & 391.572 & 0.138 & 0.138 & -1.981 & -0.273 & \\
Phrynoidis asper & 910 & 542.360 & 0.191 & 0.191 & -1.655 & -0.316 & \\
Ingerophrynus biporcatus & 773 & 460.708 & 0.162 & 0.162 & -1.818 & -0.295 & \\
Bufo melanostictus & 873 & 520.308 & 0.183 & 0.183 & -1.696 & -0.311 & 1.783 \\
Bufo bankorensis & 655 & 390.380 & 0.138 & 0.138 & -1.984 & -0.273 & \\
Bufo gargarizans & 893 & 532.228 & 0.188 & 0.188 & -1.674 & -0.314 & \\
Total & 4739 & $2,837.556$ & 1 & 1 & -10.807 & -1.783 & \\
\hline
\end{tabular}




\section{KESIMPULAN}

Berdasarkan penelitian yang telah dilakukan di Universitas Sam Ratulangi terdapat enam jenis amphibia yang ditemukan yaitu: Peltophryne lemur, Phrynoidis asper, Ingerophrynus biporcatus, Bufo melanostictus, Bufo bankorensis, dan Bufo gargarizans. Indeks keanekaragaman dari amphibia yang diamati termasuk dalam kategori sedang.

\section{SARAN}

Perlu dilakukannya penelitian lanjutan mengenai keanekaragaman amphibia ordo Caecilia, Caudata dan Anura pada setiap tipe habitat yang ada di Kampus Universitas Sam Ratulangi. Agar dapat membandingkan keanekaragaman yang berkaitan dengan kondisi spesifik tiap habitat.

\section{DAFTAR PUSTAKA}

Bibby C., Jones, M. Marsden, S. 2000. TeknikTeknik Lapangan Survei Amphibia. Birdlife Indonesia Programme. Bogor.

Duellman, W.E., Trueb L. 1994. Biologyof Amphibians. Johns Hopkins Univ. Pr,London

Duellman WE, Carpenter CC. 1998. Reptile and Amphibia Behavior. In: $\mathrm{HG}$ Cogger and RG Zweifel 1998. Encyclopedia of Reptiles and Amphibians.Second Edition. San Fransisco: Fog City Pr.

Fitri A, Mirza DK, Agus P. 2008. Keanekaragaman Jenis Amphibia (Ordo Anura) di Kebun Raya Bogor. Konservasi Amphibia dan Reptil di Indonesia. Prosiding Seminar Hasil Penelitian departemen Konservasi Sumberdaya Hutan. Bogor $8 \mathrm{Mei}$ 2003.13 (24).

Indriyanto. 2006. Ekologi Hutan. Buku. Jakarta: Bumi Aksara.

Iskandar, 1998. The amphibians of Java Bali. Research and Development Centre for Biology-LIPI-GEFBiodiversity Collection Project, Bogor.

Kusrini, M. D. (2007) Kodok merah (Leptophryne cruentata, Tschudi, 1838) Satwa yang terancampunah.Fauna Indonesia, 7(1), 25-29
Kusrini MD. 2003. Predicting the impact of the frog leg trade in Indonesia: An ecological view of the indonesian frog leg trade, emphasizing Javanese edible frog species. Dalam: MD Kusrini, A Mardiastuti dan T Harvey 2003 Konservasi Amfibi dan Reptil di Indonesia. Bogor. Fakultas Kehutanan IPB.2744.

Michael 1995. Metoda Ekologi Untuk Penyelidikan Lapangan and Laboratorium. Universitas Indonesia Press, Jakarta.

Mistar. 2003. Panduan Lapangan Amphibia Kawasan Ekosistem Leuser. Perpustakaan Nasional. Jakarta.

Mistar. 2008. Panduan Lapangan amphibia dan Reptil di Areal Mawas Propinsi Kalimantan Tengah (Catatan Hutan Lindung Beratus). Cetakan Pertama. Yayasan Penyelamatan Orangutan Borneo.Palangkaraya.

Mumpuni. 2011. Keanekaragaman Herpetofauna di Pulau Ternate and Moti, Maluku Utara. Ekologi Ternate tahun 2011:105-120

Phade AD, HT Ghate. 2002. An overvieuw of amphibia fauna of maharashtra state. Zoos print journal 17(3): 735-740

Soegianto, A. 1994.Ekologi Kuantitatif: Metode Analisis Populasi dan Komunitas. Jakarta: Penerbit Usaha Nasional.

Sparling, D. W., G. Linder , C. A. Bishop. 2000. Ecotoxicology of amphibians and reptiles. SETAC Technical Publications. Columbia. 877 hal.

Zug, G.R., H. Win., T. Thin, T. Z. Min., W. Z. Lhon., K. Kyaw. 1998. Herpetofauna of The Chatthin Wildlife Sanctuary, NorthCentral Myanmar with Preliminary Observations of Their Natural History. Hamadryad. 23(2) : 111-120 